\title{
Enteropatógenos bacterianos em peixes criados em uma estação de reciclagem de nutrientes e no ecossistema relacionado ${ }^{1}$
}

\author{
Eglaise M. Esposto ${ }^{2}$, Wanderson C. P. Silva ${ }^{3}$, Cristhiane M. F. Reis ${ }^{3}$, Eliane M. F. \\ Reis $^{3}$, Roseli V. Ribeiro ${ }^{4}$; Dália P. Rodrigues ${ }^{3}$ e Norma S. Lázaro ${ }^{3}$
}

\begin{abstract}
Esposto E.M., Silva W.C.P., Reis C.M.F., Reis E.M.F, Ribeiro R.V., Rodrigues D.P. \& Lázaro N.S. 2007. [Bacterial enteropathogens from fishes of a nutrient recycle system and its ecosystem.] Enteropatógenos bacterianos em peixes criados em uma estação de reciclagem de nutrientes e no ecossistema relacionado. Pesquisa Veterinária Brasileira 27(4):144-148. Departamento de Bacteriologia, Instituto Oswaldo Cruz, FIOCruz, Av. Brasil 4365, Pav. Rocha Lima, Manguinhos, Rio de Janeiro, RJ 21040-360, Brazil. E- mail: nslazaro@ioc.fiocruz.br

The presence of bacterial enteropathogens from fishes of a nutrient recycle system from a Experimental Station in Petropolis, RJ, was evaluated in 72 samples from april 2000 to july 2001 Simultaneously was collected the mud used as organic manure and poultry beds localized next to the tanks. The isolation procedures included preenrichment in Peptone Water followed by enrichment with alcaline Peptone Water ( $\mathrm{pH}$ 8.4-8.6), and streaked onto GSP Agar for the isolation of Aeromonas spp. and Plesiomonas shigelloides. For enteropathogenic bacteria of the Enterobacteriaceae family, $1 \mathrm{ml}$ samples were transferred for enrichment in RappaportVassiladis broth and Kauffmann Tetrathionate Broth followed by streak onto Hektoen Enteric Agar and Salmonella-Shigella Agar. Simultaneously at each visit samples of water from fish and macrophyte tanks were collected for monitoring faecal coliforms (MPN) using A1 medium. Among the 116 isolates, Aeromonas spp. were the most frequent (67.2\%) with 9 species (A. veronii, biogroup sobria, A. hidrophila, A. sobria, A. trota, A. eucrenophila, A. veronii biog. veronii, $A$. media, A. cavia and A. jandaei), followed by Edwardsiella tarda (16.4\%), Plesiomonas shigelloides $(12.9 \%)$ and Salmonella spp. (3.4\%). The NMP of fecal coliforms showed higher values in the fish tanks (>1800/100ml).
\end{abstract}

INDEX TERMS: Enteropathogens, wastewater, fish farming.

RESUMO.- Avaliou-se a presença de enteropatógenos bacterianos em 72 amostras obtidas a partir de peixes criados em sistema de reciclagem de nutrientes, em estação experimental, no município de Petrópolis, RJ. Paralelamente, foram obtidas amostras do lodo utilizado como adubo orgânico e da cama de aves

\footnotetext{
${ }^{1}$ Recebido em 25 de agosto de 2006.

Aceito para publicação em 22 de novembro de 2006.

Trabalho realizado com o apoio financeiro da Capes.

2 Discente de Pós-Graduação em Microbiologia Veterinária, Instituto de Veterinária, Universidade Federal Rural do Rio de Janeiro (UFRRJ), Seropédica, RJ 23890-000.

3 Departamento de Bacteriologia, Instituto Oswaldo Cruz, FIOCruz, Av. Brasil, 4365, Pav. Rocha Lima, Manguinhos, Rio de Janeiro, RJ 21040-360. *Autor para correspondência: nslazaro@ioc.fiocruz.br

${ }^{4}$ Doutoranda em Microbiologia Molecular, Universidade do Estado do Rio de Janeiro (UERJ).
}

localizada na área interna dos tanques criatórios. A metodologia empregada incluiu o pré-enriquecimento em Caldo Lactosado e Água Peptonada Tamponada, seguido de enriquecimento em Água Peptonada Alcalina (pH 8,4-8,6) e subseqüiente semeadura em Agar GSP para o isolamento de Aeromonas spp. e Plesiomonas shigelloides. Para os demais microrganismos, alíquotas de $1 \mathrm{ml}$ foram inoculadas nos meios de enriquecimento Caldo Rappaport-Vassiliadis e Caldo Tetrationato de Kauffmann com posterior semeadura em Agar Entérico Hektoen e Agar Salmonella-Shigella. Com a finalidade de monitorar o índice de coliformes fecais, visando conhecer a qualidade da água para este sistema, paralelamente à coleta de peixes foram avaliadas amostras de água dos tanques criatórios e de macrófitas. No cômputo geral foram isoladas 116 cepas de enteropatógenos bacterianos, destacando-se Aeromonas spp $(67,2 \%)$ com 9 espécies (A. veronii biogrupo sobria, A. hydrophila, A. sobria, A. trota, 
A.eucrenophila, A. veronii biog. veronii, A. media, A. caviae e $A$ jandaei) e Aeromonas spp., seguido de Edwardsiella tarda (16,4\%), Plesiomonas shigelloides $(12,9 \%)$ e Salmonella $(3,4 \%)$. A análise da qualidade da água empregada no sistema revelou, de um modo geral, índices mais elevados de coliformes fecais nos tanques dos peixes $(>1800 / 100 \mathrm{ml})$.

TERMOS DE INDEXAÇÃO: Enteropatógenos, águas residuárias, piscicultura.

\section{INTRODUÇÃO}

A produção de pescado no Brasil vem crescendo sob a influência da expansão da piscicultura de água doce, embora o seu consumo esteja aquém, quando comparado ao das outras fontes de proteína de origem animal (Oetterer 1991). Atualmente, estimula-se esta atividade através da piscicultura alternativa, como por exemplo através da reutilização da água de efluentes domésticos na manutenção dos tanques criatórios (Valenti et al. 2000 ).

Sob condições controladas de tratamento, as águas residuárias podem ser utilizadas na criação de peixes e o adubo orgânico resultante, empregado para o cultivo de hortaliças, além de possibilitar o seu uso como fonte energética, representando deste modo um baluarte para a economia de alguns países (WHO 1989). Neste contexto a aqüicultura moderna apóia-se na produção lucrativa, preservação do meio ambiente e desenvolvimento social (Valenti et al. 2000). Porém sob o aspecto de saúde pública, a literatura aponta para que uma minuciosa e constante análise microbiológica seja implementada na produção oriunda deste tipo de sistema, tendo em vista a possibilidade de veiculação de patógenos diretamente associados a infecção de origem alimentar (WHO 1989).

Dentre os agentes bacterianos amplamente distribuídos no ecossistema aquático, destacam-se aqueles pertencentes às famílias Aeromonadaceae e Enterobacteriaceae, cuja presença nesse ambiente pode ser reconhecida através de sua detecção na pele, brânquias e intestinos dos peixes e, quando há desequilíbrio do sistema bactéria-hospedeiro-ambiente, podem estar envolvidos como agentes etiológicos primários, inclusive desencadeando epizootias em piscicultura (Lehane \& Rawlin 2000, Francis-Floye 2002, Huber et al. 2004). Acrescenta-se ainda a capacidade de acometer uma gama variada de animais, incluindo o homem, destacando-se as espécies do gênero Aeromonas descritas como patógenos emergentes de importância crescente em alimentos e Plesiomonas shigelloides, ambos envolvidos em infecções intestinais e extraintestinais (Lehane \& Rawlin 2000).

Na família Enterobacteriaceae, incluem-se alguns dos patógenos intestinais mais importantes, reconhecidos por sua elevada freqüência como Salmonella, Yersinia, Shigella e alguns tipos patogênicos de Escherichia coli, bem como outros cuja freqüência é reduzida, mas que podem ser responsáveis por surtos diarréicos (Murray et al. 1998). Neste contexto, ressaltam-se os representantes do gênero Edwardsiella, que vêm sendo considerados patógenos emergentes entre as enfermidades de origem alimentar (Janda \& Abbott 1993).

Considerando a discreta bibliografia especializada sobre o assunto e a carência de avaliações, em nosso meio, sobre a qualidade dos produtos resultantes da reciclagem de nutrientes como método sustentável em piscicultura, a presente investigação teve como objetivo avaliar a qualidade bacteriológica dos peixes produzidos em sistema de cultivo integrado e no ecossistema relacionado (cama de aves e adubo orgânico) através da detecção de enteropatógenos bacterianos pertencentes às famílias Enterobacteriaceae e Aeromonadaceae, além de monitorar o índice de coliformes fecais presentes na água residual submetida ao tratamento primário e utilizada no cultivo do pescado.

\section{MATERIAL E MÉTODOS}

\section{Amostragem}

A colheita de espécimes foi realizada em uma estação experimental de tratamento de águas residuárias, utilizando sistema de lagoa de estabilização, localizada em Sertão de Carangola, Petrópolis, RJ, durante o período de abril de 2000 a julho de 2001. A amostragem constituiu-se de peixes Tilapia nilotica (Oreochromis niloticus), criados neste sistema de reciclagem de nutrientes, do lodo utilizado como adubo orgânico e cama de aves. Foram analisados um pool de três a cinco peixes capturados a cada visita. Nos alevinos, procedeu-se a análise do lavado de superfície corporal, enquanto nos adultos os espécimes foram obtidos a partir de procedimentos de necropsia representados por guelras, vísceras (fígado, baço e intestinos), superfície corporal (pele) e musculatura dorso-lateral.

Para avaliação da presença de enteropatógenos bacterianos no lodo utilizado como adubo orgânico, foram retiradas amostras $( \pm 100 \mathrm{~g})$ da profundidade $( \pm 50 \mathrm{~cm})$ e, na cama de patos e galinhas mantidos em criadouro na área interna do tanque, foram obtidas amostras representativas da superfície (10-20g). Efetuou-se um total de 72 análises, compreendendo 17 de cama de aves, 10 de adubo orgânico, 9 de lavado da superfície corpórea dos alevinos e, dos peixes adultos, pele, musculatura, guelras e vísceras ( 9 de cada).

Como controle de qualidade da água utilizada neste sistema, foram colhidas amostras de $100 \mathrm{ml}$ nos dois tanques de peixes, totalizando 28 análises e nos dois tanques de macrófitas (20 análises) contíguos aos dos peixes.

Os espécimes foram acondicionados em sacos plásticos, mantidos em recipiente isotérmico à temperatura de $8-10^{\circ} \mathrm{C}$ com conservador biológico e processados no mesmo dia da aquisição.

\section{Isolamento e identificação bioquímica e antigênica}

Nas amostras de alevinos, foi efetuada lavagem da superfície corpórea em solução salina de Butterfield e, em sequiência, préenriquecimento em água peptonada (pH 7,6) e em caldo lactosado, na proporção 1:10, o mesmo empregado para o lodo. As amostras obtidas de peixes adultos, após serem trituradas e maceradas em gral e pistilo, foram submetidas ao mesmo procedimento. Na etapa subseqüiente, $1 \mathrm{ml}$ de cada caldo de cultivo foi enriquecido em Água Peptonada Alcalina (APA, pH 8,4-8,6), Caldo Rappaport-Vassiliadis (Merck) e Caldo Tetrationato de Kauffmann (Merck), com posterior semeadura nos meios seletivos indicadores Agar Entérico Hecktoen (Difco), Agar Salmonella-Shigella (Agar SS, Merck) e Agar GSP (Agar Seletivo para Pseudomonas-Aeromonas, Merck).

No processamento das amostras de cama de aves, procedeu-se apenas ao enriquecimento em APA, Caldo Rappaport-Vassiliadis e Caldo Tetrationato de Kauffmann e semeadura nos meios seletivos-indicadores. Todas as etapas foram submetidas à incubação a $37^{\circ} \mathrm{C}$ por 18 a 24 horas, com exceção do caldo Rappaport $\left(43^{\circ} \mathrm{C}, 18-24 \mathrm{~h}\right)$. Colônias suspeitas foram inoculadas em Agar Ferro-Três Açúcares (TSI Agar- Merck) e Agar Lisina Ferro (LIA, Merck), além da determinação da presença da enzima citocromo-oxidade, em Agar Nutriente visando a caracterização bioquímica presuntiva. Para a identificação bioquímica complementar foram adotadas as especificações de Costa \& Hofer (1972) e Janda et al. 
(1995). Nesta etapa, foram realizadas as provas da fermentação de carboidratos e correlatos tais como: glicose, lactose, manitol e sacarose; descarboxilação da lisina e ornitina; dehidrolação da arginina; pesquisa da produção de indol e sulfeto de hidrogênio; motilidade, prova de Voges-Proskauer (VP), Vermelho de Metila (VM) e utilização do citrato como única fonte de carbono. Para as amostras citocromo-oxidase positivas, além das provas descritas acima, foram realizados os testes de fermentação de arabinose e manose e a determinação da resistência ao agente vibriostático 0/129 (2,4 diamino 6,7 diisopropilpteridina).

Os isolados de Salmonella foram caracterizados antigenicamente através da técnica de soro-aglutinação rápida, em lâmina, com antisoros poli e monovalentes, somáticos e flagelares, preparados no Departamento de Bacteriologia do Instituto Oswaldo Cruz, FIOCruz, Rio de Janeiro. A caracterização dos sorovares foi realizada com base no esquema sorológico de Kauffmann-White e suas representações obedecendo aos critérios de Popoff \& Le Minor (2003).

Determinação do Número Mais Provável de Coliformes Fecais (NMP)

Realizada em tubos contendo meio A1, de acordo com a metodologia preconizada pela Organização Mundial de Saúde (WHO 1996). Uma alíquota de $100 \mathrm{ml}$ da água oriunda dos tanques foi inicialmente homogeneizada e, a seguir, diluída em salina na proporção 1:10. Desta, adicionou-se $1 \mathrm{ml}$ em cada um dos cinco tubos contendo $5 \mathrm{ml}$ de meio A1, procedendo-se a incubação a $44^{\circ} \mathrm{C}\left( \pm 0,25^{\circ} \mathrm{C}\right)$, por um período de 24 horas.

\section{RESULTADOS E DISCUSSÃO}

A análise dos espécimes permitiu isolar e identificar 116 cepas de enteropatógenos bacterianos em 16 das 18 coletas (Quadro 1), caracterizadas em quatro gêneros: Aeromonas (78-67,2\%), Plesiomonas (15-12,9\%), Edwardsiella (19-16,4\%) e Salmonella (4-3,4\%).

A análise comparativa quanto ao isolamento dos diferentes enteropatógenos em função das coletas, evidenciou que Aeromonas spp. foi detectada em 16 das $18(88,8 \%)$ coletas efetuadas, Plesiomonas shigelloides em 10 (55,5\%), Edwardsiella tarda em $8(44,4 \%)$ e Salmonella em $2(11,1 \%)$.

Esses dados retratam a ampla disseminação de Aeromonas spp. confirmando as observações de outros autores que destacam a ocorrência bastante freqüente desses microrganismos no ambiente aquático, principalmente em água doce, peixes e outras fontes (Bremer et al. 2003, Huber et al. 2004). Diferente de outros enteropatógenos, Aeromonas spp. não necessita de um hospedeiro humano ou animal mamífero para sobreviver e/ou multiplicar, sobrevivendo no ambiente aquático e constituindo a microbiota das águas superficiais. $\mathrm{O}$ ciclo fecal-oral pode contribuir para o aumento do número de bactérias no ambiente, entretanto este número é determinado muito mais por fatores ecológicos do que por contaminação humana (King et al. 1992).

Ainda no Quadro 1 são apresentados os valores da contagem de coliformes fecais nos espécimes analisados. Salienta-se que os resultados correspondentes a cada mês, são representados pelos dois valores encontrados, salvo quando são iguais.

A análise da água dos tanques das tilápias apresentou, na maioria das vezes, concentrações $>1800$ coliformes fecais. Estes valores estão acima dos padrões preconizados pela Organização Mundial de Saúde (WHO 1989) que estabelece $\leq 10^{3}$ coliformes fecais/100ml como limite de qualidade nos tanques piscícolas. Em relação aos tanques de macrófitas, as coletas foram efetuadas no período de outubro/2000 a julho/2001, com índices de coliformes fecais $>1800 / 100 \mathrm{ml}$ em quatro das 20 análises. As menores concentrações de coliformes fecais nos tanques de macrófitas quando comparadas às dos peixes encontram respaldo nas observações de Souza et al. (2001, 2004), que constataram a influência da presença de macrófitas na redução de coliformes.

Analisando o Quadro 2, verifica-se que, entre os isolados de Aeromonas, as maiores frequiências originaram-se de músculo e superfície corporal (19 de 78 isolados, $24,3 \%$ ) e do lavado de superfície de alevinos $(12,15,4 \%)$. Em relação a E. tarda e Plesiomonas (não computados em quadro), os maiores percentuais foram obtidos a partir de vísceras $(36,8 \%$ - 7 de 19 isolados e 26,6\%, 4 de 15 isolados, respectivamente) e de guelras (26,3\% e $26,6 \%$, respectivamente). $\mathrm{O}$ isolamento desses enteropatógenos nos diferentes espécimes obtidos de peixes reflete na qualidade da carne do pescado. Ogawa \& Maia (1999) citam que músculos, órgãos e líquido corporal de peixes vivos saudáveis são livres de microrganismos, enquanto que a pele e guelras, por estarem em contato com a água, apresentam um razoável nível de contaminação.

Segundo Strauss (1985), a invasão da musculatura dos peixes por bactérias é muito provável ocorrer quando estes crescem

Quadro 1. Distribuição das espécies/gêneros de enteropatógenos bacterianos de acordo com os meses de coleta e a contagem de coliformes fecais (NMP)

Relação colifor- _ 2000(meses) 2001(meses)

mes fecais (NMP) Abril Maio Junho Junho Julho Julho Agosto Agosto Setembro Outubro Novembro Dezembro Janeiro Fevereiro Abril Maio Junho Julho Total gêneros espécies

bacterianas

\begin{tabular}{|c|c|c|c|c|c|c|c|c|c|c|c|c|c|c|c|c|c|c|c|}
\hline \multirow{5}{*}{ NMP } & \multicolumn{19}{|c|}{ Tanque de peixes (2) } \\
\hline & 1600 & 910 & $>1800$ & $>1800$ & 910 & $>1800$ & 1600 & $>1800$ & $>1800$ & $>1800$ & $540 \mathrm{e}$ & $>1800$ & $240 \mathrm{e}$ & 1600 & $910 \mathrm{e}$ & $1600 \mathrm{e}$ & $1600 \mathrm{e}$ & $>1800$ & \\
\hline & & & & & & & & & & & 1600 & & 910 & & $>1800$ & $>1800$ & $>1800$ & & \\
\hline & \multicolumn{19}{|c|}{ Tanque de macrófitas(2) } \\
\hline & $\mathrm{Nd}^{\mathrm{a}}$ & $\mathrm{Nd}$ & $\mathrm{Nd}$ & $\mathrm{Nd}$ & Nd & $\mathrm{Nd}$ & Nd & $\mathrm{Nd}$ & $\begin{array}{c}240 \mathrm{e} \\
>1800\end{array}$ & $\begin{array}{c}240 \mathrm{e} \\
350\end{array}$ & $\begin{array}{c}350 \mathrm{e} \\
240\end{array}$ & $>1800$ & $\begin{array}{c}240 \mathrm{e} \\
>1800\end{array}$ & $\begin{array}{c}350 \mathrm{e} \\
910\end{array}$ & $\begin{array}{c}240 \mathrm{e} \\
1600\end{array}$ & $>1800$ & 240 & 240 & \\
\hline Aeromonas spp. & 2 & 1 & 12 & 3 & 3 & - & 2 & - & 3 & 13 & 6 & 11 & 7 & 5 & 2 & 2 & 5 & 1 & $78(67,2)$ \\
\hline P. shigelloides & & 1 & 1 & - & 1 & - & - & - & - & 2 & 3 & 1 & 3 & 1 & - & - & 1 & 1 & $15(12,9)$ \\
\hline E. tarda & & - & 1 & - & - & - & - & - & - & 1 & 3 & 4 & 3 & - & 3 & - & 3 & 1 & $19(16,4)$ \\
\hline Salmonella spp. & & - & - & - & - & - & - & - & - & - & 3 & 1 & - & - & - & - & - & - & $4(3,4)$ \\
\hline Total $^{\mathrm{b}}$ & $\begin{array}{c}2 \\
(1,7)\end{array}$ & $\begin{array}{c}2 \\
(1,7)\end{array}$ & $\begin{array}{c}14 \\
(12,1)\end{array}$ & $\begin{array}{c}3 \\
(2,6)\end{array}$ & $\begin{array}{c}4 \\
(3,4)\end{array}$ & - & $\begin{array}{c}2 \\
(1,7)\end{array}$ & - & $\begin{array}{c}3 \\
(2,6)\end{array}$ & $\begin{array}{c}16 \\
(13,7)\end{array}$ & $\begin{array}{c}15 \\
(12,9)\end{array}$ & $\begin{array}{c}17 \\
(14,6)\end{array}$ & $\begin{array}{c}13 \\
(11,2)\end{array}$ & $\begin{array}{c}6 \\
(5,2)\end{array}$ & $\begin{array}{c}5 \\
(4,3)\end{array}$ & $\begin{array}{c}2 \\
(1,7)\end{array}$ & $\begin{array}{c}9 \\
(7,7)\end{array}$ & $\begin{array}{c}3 \\
(2,6)\end{array}$ & 116 \\
\hline
\end{tabular}

\footnotetext{
a Não determinado.

b Percentuais calculados sobre o total de isolados (116).
} 
Quadro 2. Freqüência e distribuição dos gêneros/espécies bacterianas de acordo com os diferentes espécimes examinados

\begin{tabular}{|c|c|c|c|c|c|c|c|}
\hline \multirow[t]{2}{*}{ Espécies } & \multicolumn{6}{|c|}{ Espécimes } & \multirow{2}{*}{$\begin{array}{c}\text { Total } \\
\mathrm{n}=62 \\
(\%)^{\mathrm{a}}\end{array}$} \\
\hline & $\begin{array}{c}\text { Alevinos } \\
(n=9)\end{array}$ & $\begin{array}{l}\text { Pele } \\
(n=9)\end{array}$ & $\begin{array}{c}\text { Músculo } \\
(\mathrm{n}=9)\end{array}$ & $\begin{array}{c}\text { Guelras) } \\
(n=9)\end{array}$ & $\begin{array}{c}\text { Vísceras } \\
(\mathrm{n}=9)\end{array}$ & $\begin{array}{c}\text { Cama } \\
(\mathrm{n}=17)\end{array}$ & \\
\hline A.veronii biog sobria & 4 & 6 & 4 & 2 & 1 & 1 & $18(29,0)$ \\
\hline A.sobria & 1 & 1 & 2 & 2 & 2 & 2 & $10(16,1)$ \\
\hline A. veronii biog.veronii & & & & & 1 & & $1(1,6)$ \\
\hline A. trota & 1 & 1 & 1 & & 1 & & $4(6,4)$ \\
\hline A. hydrophila & 1 & 2 & 3 & 1 & 1 & 2 & $10(16,1)$ \\
\hline A. eucrenophila & 1 & 1 & 2 & & & & $4(6,4)$ \\
\hline A caviae & & & & & 1 & & $1(1,6)$ \\
\hline A. jandaei & & & 1 & & & & $1(1,6)$ \\
\hline A. media & & & 1 & & & & $1(1,6)$ \\
\hline Aeromonas spp. & 4 & 8 & 5 & 4 & 3 & 4 & $28(45,1)$ \\
\hline Subtotal ${ }^{b}$ & $12(15,4)$ & $19(24,3)$ & $19(24,3)$ & $9(11,5)$ & $10(12,8)$ & $9(11,5)$ & 78 \\
\hline P. shigelloides & 1 & 2 & 1 & 4 & 4 & 3 & $15(24,2)$ \\
\hline E.tarda & 1 & 2 & 3 & 5 & 7 & 1 & $19(30,6)$ \\
\hline $\begin{array}{r}\text { Salmonella } \\
\text { 0:17 }\end{array}$ & & 1 & & 1 & 1 & & $3(4,8)$ \\
\hline $\begin{array}{c}\text { Salmonella spp. } \\
\text { (imóvel) }\end{array}$ & & & & 1 & & & $1(1,6)$ \\
\hline Total $^{\mathrm{c}}$ & $13(11,2)$ & $24(20,7)$ & $23(19,8)$ & $20(17,2)$ & $22(19,0)$ & $13(11,2)$ & 116 \\
\hline
\end{tabular}

\footnotetext{
a \% calculada sobre os 62 espécimes analisados.

b \% calculada sobre os 78 isolados.

c \% calculada sobre os 116 isolados.
}

em lagoas contendo concentrações de coliformes fecais e salmonelas, maiores que $10^{4}$ e $10^{5}$ por $100 \mathrm{ml}$, respectivamente; o potencial de invasão do músculo aumenta com a duração da exposição do peixe à água contaminada. Algumas evidências sugerem que existem poucos organismos entéricos patogênicos nos peixes quando a concentração de coliformes fecais na água é $<10^{3} / 100 \mathrm{ml}$, no entanto, mesmo em baixos níveis de contaminação pode haver alta concentração de patógenos no trato digestivo ou fluidos peritoniais do peixe podendo contaminar a carne e outras partes comestíveis, constituindo um fator de risco ao consumidor, se os padrões de higiene são inadequados.

O elevado índice de isolamento de Aeromonas a partir das amostras de superfície (alevinos, 15,4\% e de adultos, 24,3\%), pode estar relacionado ao fato destes microrganismos terem a capacidade de produzir diversas proteases, como quitinase, gelatinase, elastase, lipase, lecitinase as quais contribuem para a patogenicidade nos mais diversos hospedeiros, causando danos diretos aos tecidos ou potencializando a capacidade de invasão (Sakai 1985). Cabe ressaltar que, segundo alguns autores essas proteases são mais importantes na patogenia de peixes, do que os fatores hemolíticos e enterotóxicos associados com doenças no homem, o que sob o aspecto econômico pode ser um fator relevante no comprometimento do plantel (Cahill 1990).

Sob a ótica de saúde pública, o consumo de peixes oriundos de tanques consorciados com dejetos orgânicos de origem humana, adverte para o cuidado na manipulação no momento da retirada das vísceras e no preparo do produto, pois esta é uma via potencial de transmissão de bactérias patogênicas (Strauss 1985).

A análise da cama de aves permitiu o isolamento de Aeromonas em 9 dos 17 espécimes (52,9\%), P. shigelloides em 3 análises (17,6\%) e $E$. tarda (1-14,3\%). Cabe salientar que, em relação ao adubo orgânico não foi detectada a presença desses enteropatógenos na totalidade dos espécimes (10 análises), acusando, porém, um predomínio de outros membros da família Enterobacteriaceae e Pseudomonadaceae.

No que se refere ao aspecto ecológico destes microrganismos a detecção de Aeromonas na cama de aves ressalta a importância desses animais como possíveis fontes de infecção nesse ecossistema, compatibilizando-se com a literatura de que membros deste gênero são isolados do trato intestinal de animais endotérmicos, bem como de produtos de origem animal incluindo a carne bovina e de aves, leite e outros (Fricker \& Tompsett 1989), estando também envolvidos em casos de doença (Lázaro et al. 1987).

Considerando-se apenas a análise dos 62 espécimes oriundos de alevinos, peixes adultos e cama de aves, os quais foram positivos para os microrganismos pesquisados, salienta-se que foram identificadas 9 espécies de Aeromonas, predominando $A$. veronii biogrupo sobria em 18 dos 62 espécimes (29,0\%), seguido de $A$. hydrophila e A. sobria (10, 16,1\%), A. trota e A. eucrenophila (4-6,4\%), A. veronii biog. veronii, $A$. media, $A$. caviae e $A$ jandaei (1 isolado, 6,4\%); 28 cepas $(45,1 \%)$ foram caracterizadas como Aeromonas spp. não tendo sido possível a identificação de espécie com base nos testes bioquímicos (Quadro 2).

Sob o aspecto de saúde pública, alguns autores consideram que somente $A$. hydrophila, $A$. veronii biogrupo sobria e $A$. caviae são patógenos intestinais e, em menor grau $A$. trota e $A$. eucrenophila (Camahan 1993, Janda \& Abbott 1998), embora já tenham sido responsabilizados por infecções extraintestinais, como bacteremia, septicemia, pneumonia e celulite, principalmente em indivíduos debilitados imunologicamente (Janda \& Abbott 1998). Por outro lado, A. schubertii, A. jandaei e $A$. veronii biog. veronii são, na maioria das vezes, isolados de patologias extra-intestinais (Janda \& Abbott 1998). 
Quanto a P. shigelloides (Quadro 2), foram detectadas 15 cepas $(24,2 \%)$ resultantes dos 62 espécimes nas 18 coletas efetuadas. A exemplo dos dados obtidos em relação a Aeromonas, nossos achados confirmam as observações de outros autores, de que esta espécie é amplamente distribuída, ocorrendo em peixes e outros animais típicos do ambiente aquático, predominando em águas fluviais (Hernandes \& Garcia 1997, Huber et al. 2004). A bactéria também tem sido isolada de água do mar contaminada por esgoto, sedimentos, lodos, trato intestinal de animais domésticos e silvestres e, no homem, vem sendo incriminada em infecções de origem alimentar (Khardori \& Fainstein 1988), ocorrendo de forma esporádica ou surtos de diarréia em diferentes regiões do mundo, assim como em infecções extra-intestinais caracterizadas por colecistite, septicemia e outras. (Fariñas et al. 1998).

Acrescenta-se ainda que a presença de $E$. tarda foi detectada em 30,6\% dos 62 espécimes analisados. Esta espécie vem sendo responsabilizada por casos de gastrenterite e infecções de feridas no homem (Janda \& Abbott 1993), estando incluída na classificação de risco Categoria 2 (risco moderado), estabelecida pela Comissão Técnica Nacional de Biossegurança - CNTBio (Brasil 1997), alertando-se ainda para os possíveis riscos de contaminação resultantes da manipulação inadequada do pescado, bem como do seu consumo.

Da mesma forma, a presença de Salmonella nos peixes analisados reveste-se de importância pelo seu mecanismo de veiculação através de alimentos, sendo freqüientemente incriminada em casos de gastrenterite no homem (Isonhood \& Drake 2002).

De acordo com o Regulamento Técnico sobre Padrões Microbiológicos para Alimentos, Resolução RDC $n^{\circ}=12$, de 2 de janeiro de 2001 (Brasil 2001), a presença de Salmonella em 25g de pescado in natura, torna-o impróprio para consumo humano.

Os resultados obtidos no presente estudo apontam para a necessidade de adoção de procedimentos que visem reduzir os índices de contaminação e, consequentemente, o risco potencial desses microrganismos para o consumidor tendo em vista a possibilidade de contaminação cruzada se os padrões de higiene no preparo de alimentos forem inadequados.

\section{REFERÊNCIAS}

Brasil 1997. Instrução Normativa nำ. Diário Oficial, Republica Federativa do Brasil, Brasília, 9 de jun., Seção 1, p.11.824-11.833.

Brasil 2001. Ministério da Saúde, Agência de Vigilância Sanitária. Resolução RDC no 12 de 2 de janeiro de 2001. In: Associação Brasileira das Industrias de Alimentos. Compêndio de Legislação de Alimentos. Vol.1/ A. São Paulo.

Bremer P.J., Fletcher C.G. \& Osborne C. 2003. Aeromonas spp. in seafood. New Zealand Institute for Crop \& Food Research, Christchurch. 6p.

Cahill M.M. 1990. Virulence factor in motile Aeromonas: a review. J. Appl. Bacteriol. 16:1-16.

Camahan A.M. 1993. Aeromonas taxonomy: a sea of change. Med. Microbiol. Lett. 2:206-211.

Costa G.A. \& Hofer E. 1972. Isolamento e Identificação de Enterobactérias. Monogr., Inst. Oswaldo Cruz, Rio de Janeiro. 120p,

Fariñas L.B., Almeida O.S.P., Mesa J.M., Álvarez M.R. \& Rodríguez B.G. 1998. Susceptibilidad antimicrobiana y aislamiento de plásmidos en Plesiomonas shigelloides. Revta Cubana Med. Trop. 50:203-206.
Francis-Floyd R. 2002. Aeromonas Infections. IFAS - Institute of Food and Agricultural Sciences. FA14.

Fricker C.R. \& Tompsett S. 1989. Aeromonas spp. in foods: a significat cause of food poisoning? Int. J. Food Microbiol. 9:17-23.

Hernandez P. \& Garcia R.R. 1997. Prevalence of Plesiomonas shigelloides in surface water. Arch. Latinoam. Nutr. 47:47-49.

Huber I., Spanggaard B., Appel K.F., Rossen L., Nielsenand T. \& Gram L. 2004. Phylogenetic analysis and in situ identification of the intestinal microbial community of rainbow trout (Oncorhynchus mykiss, Walbaum). J. Appl. Microbiol. 96:117.

Isonhood J.H. \& Drake M. 2002. Aeromonas species in foods. J. Food Protect. 65:575-582.

Janda J.M. \& Abbott S.L. 1998. Evolving concepts regarding the genus Aeromonas: an expanding panorama of species, disease presentations, and unanswered questions. Clin. Infect. Dis. 27:332-344.

Janda J.M. \& Abbott S.L. 1993. Infections associated with the genus Edwardisiella: the role of Edwardsiella tarda in human disease. Clin. Infect. Dis. 17:742-748.

Janda J.M., Abbott S. \& Carnaham M. 1995. Aeromonas and Plesiomonas. In: Murray P., Baron E., Pfaller M., Tenover F. \& Yolken R. (ed.), Manual of Clinical Microbiology. Sixth Edition. American Society of Microbiology, Washington, D.C.

Khardori N. \& Fainstein V. 1988. Aeromonas and Plesiomonas as etiological agentes. Ann. Revta Microbiol. 42:395-419.

King F.G., Werner S.B. \& Kizer K.W. 1992. Epidemiology of Aeromonas infections in California. Clin. Infect. Dis. 15:449-452.

Lázaro N.S., Hofer E., Mendonça G.A. \& Britto M.S.M. 1987. Isolamento e caracterização de Aeromonas hydrophila em um cisne (Cygnus olor). Revta Bras. Med. Vet. 9:83-85.

Lehane L. \& Rawlin G.T. 2000. Tropically acquired bacterial zoonoses from fish: a review. Med. J. Aust. 173:256-259.

Murray P.R., Rosental K.S., Kobayashi G.S. \& Pfaller M.A. 1998. Medical Microbiology $3^{\text {th }}$ ed. Mosby-Year Book, St Louis, Missouri. 719p

Oetterer M. 1991. Matéria Prima Alimentar: pescado. Centro de Pesquisa do Instituto Mauá de Tecnologia, São Caetano Sul. 29p.

Ogawa M. \& Maia L.1999. Manual de Pesca. Livraria Varela, São Paulo.

Popoff M.Y. \& Le Minor L. 2003. Antigenic formulas of the Salmonella serovars. WHO Collaborating Centre for Reference and Research on Salmonella. Institute Pasteur, Paris.

Sakai D.K. 1985. Loss of virulence in a protease-deficience mutant of Aeromonas salmonicida. Infect. Immun. 48:146-152.

Sousa J.T., van Haandel A.C. \& Guimarães A.V.A. 2001. Post-treatment of anaerobic effluents in constructed wetland systems. Water Sci. Technol. 44:213-219.

Sousa J.T., van Haandel A.C., Lima E.P.C. \& Henrique I.N. 2004. Utilização de Wetland Construído no Pós-Tratamento de Esgotos Domésticos PréTratados em Reator UASB. Eng. Sanit. Ambient, Rio de Janeiro, 9:285290.

Strauss M. 1985. Health Aspects of Nightsoil and Sludge in Agriculture and Aquaculture. Part II. Pathogen Survival. Int. Ref. Center of Waste Disposal (IRCWD), No.4/85, 87p.

Valenti W.C., Poli C.R., Pereira J.A. \& Borgheth J.R. 2000. Aqüicultura no Brasil: bases para um desenvolvimento sustentável. Conselho Nacional de Desenvolvimento Cientifico e Tecnológico (CNPq), Ministério da Ciência e Tecnologia, Brasília, DF. 399p.

WHO 1989. Health Guidelines for the Use of Wastewater in Agriculture and Aquaculture. WHO Technical Report Series no.778, Geneva.

WHO 1996. Analyzes of Wastewater for Use in Agriculture: a laboratory manual of parasitological and bacteriological techniques. Word Health Organization, Geneva. 35p. 